\title{
Lanthanide and actinide extractions with cobalt bis(dicarbollide) ion derivatives covalently bonded to diglycolyl diamide platform
}

\author{
By M. Lučaníková ${ }^{1, *}$, P. Selucký ${ }^{1}$, J. Rais ${ }^{1}$, B. Grüner ${ }^{2}$ and M. Kvíčalová \\ ${ }^{1}$ Nuclear Research Institute plc., 25068 Řež near Prague, Czech Republic \\ ${ }^{2}$ Institute of Inorganic Chemistry, Academy of Sciences of the Czech Republic, v.v.i., 25068 Řež near Prague, Czech Republic
}

(Received December 19, 2009; accepted in final form December 20, 2010)

\begin{abstract}
Dicarbollides derivates / TODGA /
Liquid-liquid extraction / Lanthanides / Actinides /

High-level waste
\end{abstract}

Summary. The separation of minor actinides from highlevel waste (HLW) remains a difficult problem. A wide series of compounds based on two cobalt bis(dicarbollide) ions $\left[\left(1,2-\mathrm{C}_{2} \mathrm{~B}_{9} \mathrm{H}_{10}\right)\left(1^{\prime}, 2^{\prime}-\mathrm{C}_{2} \mathrm{~B}_{9} \mathrm{H}_{11}\right)-3,3^{\prime}-\mathrm{Co}(\mathrm{III})\right]^{-}$(COSAN) covalently bonded to a diglycolyl amide platform via diethyleneglycol connectors was prepared by reaction of the diglycolic acid dichloride with various ammonium derivatives of the COSAN with the aim to develop new class of extractants for trivalent radionuclides from acidic waste solutions. The extractants of general formulation $\quad\left[\left\{\left(\mathrm{N}, \mathrm{N}-\left(8-\mathrm{CH}_{2}-\mathrm{CH}_{2} \mathrm{O}\right)_{2}-1,2-\mathrm{C}_{2} \mathrm{~B}_{9} \mathrm{H}_{10}\right)\left(1^{\prime}, 2^{\prime}-\mathrm{C}_{2} \mathrm{~B}_{9} \mathrm{H}_{11}\right)-\right.\right.$ $\left.\left.\left.3,3^{\prime}-\mathrm{Co}\right)\left(\mathrm{N}, \mathrm{N}^{\prime}-\mathrm{R}\right) \mathrm{NCOCH}_{2}\right\}_{2}-\mathrm{O}\right] \mathrm{Na}_{2}$ differed in substitution on the amidic nitrogen (by e.g. butyl-, hexyl-, octyl-, $t$-octyl-, dodecyl-, benzyl-groups). Compounds were characterized by combination of ${ }^{11} \mathrm{~B},{ }^{1} \mathrm{H}$ and ${ }^{13} \mathrm{C}$ NMR spectroscopy, ESIMS, HPLC, and TLC $R_{\mathrm{F}}$. The purity of all species was better than $98 \%$. Most of the compounds proved to be very efficient extraction agents and enabled effective extraction of europium(III) and americium(III) from nitric acid solutions. The recovery of the trivalent radionuclides from the loaded organic phase was possible by using ammonium citrate or even better by using solution of ammonium citrate and ammonium DTPA (diethylenetriamine pentaacetate).

\section{Introduction}

The partitioning and transmutation of long-lived nuclides, mainly the minor actinides $\left({ }^{241,243} \mathrm{Am},{ }^{245} \mathrm{Cm},{ }^{237} \mathrm{~Np}\right)$, from high-level waste (HLW) resulting from nuclear fuel reprocessing is being proposed to reduce the amount and the longterm environmental burden of HLW. For the partitioning of minor actinides and lanthanides several hydrometallurgical processes have been investigated during the last decades, e.g. TRUEX, DIAMEX, DIDPA, TRPO based respectively on octyl-(phenyl)- $N, N$-diisobutylcarbamoylmethyl phosphine oxide (CMPO), $N, N, N^{\prime}, N^{\prime}$-dimethyldibutyltetradecylmalonamide (DMDBTDMA), diisodecylphosphoric acid (DIDPA), trialkyl phosphine oxide (TRPO) as extractants [1-5]. Recently, another class of extractants from the

\footnotetext{
*Author for correspondence (E-mail: luc@ujv.cz).
}

family of diamides, the tridentate ligands like $N, N, N^{\prime}, N^{\prime}$ tetra(n-octyl)-3-oxapentane-1,5-diamide (tetra- $n$-octyl-diglycolamide, TODGA) were proposed for the recovery of actinides/lanthanides in the HLW treatment $[6,7]$. In the frame of the UNEX process, another CMPO compound, $v i z$. diphenyl- $N, N$-di- $n$-butylcarbamoylmethyl phosphine oxide is used with a synergist chloroprotected cobalt bis(dicarbollide) [8].

In the past years, several new extractants based on combinations of the cobalt bis(dicarbollide) ion $\left(1^{-}\right),[(1,2-$ $\left.\left.\left.\mathrm{C}_{2} \mathrm{~B}_{9} \mathrm{H}_{11}\right)_{2}-3-\mathrm{Co}\right)\right]^{-}(\mathrm{COSAN})$ in single molecules with different metal chelating groups (e.g. CMPO) for the partitioning of trivalent radionuclides were developed $[9,10]$. The COSAN is negatively charged $\left(1^{-}\right)$strongly hydrophobic anion that belongs to the class of electron deficient 26-electron 12-vertex icosahedral closo borane cluster family, known for its extraordinary high chemical and thermal stability, hydrophobicity and inorganic super acid behavior $[11,12]$. The covalent bonding of COSAN with structural analogues of CMPO chelating groups into a single molecule significantly enhances extraction efficiency for trivalent radionuclides from nuclear waste solutions in comparison with "classical" CMPO ligands or their synergetic mixtures with halogenated COSANs $[9,10]$. An even more drastic increase of the extraction efficiency was observed for other extractants based on the calix[4]arene bearing combination of COSAN groups and CMPO groups. Extraction with most of the extractants of this class, which contain two COSAN and two CMPO groups, is more than four orders of magnitude higher compared to various synergistic mixtures of calix[4]arenes substituted with two CMPO groups, calix[4]arenes substituted with two COSAN groups, "classical" CMPO ligands and COSANs [13].

Recently, a new class of extractants based on two COSAN anions covalently bound to an organic, diglycolic acid platform by amidic bonds was developed. As the preliminary extraction experiments have shown, the covalent bonding of ionic COSAN with chelating TODGA-like groups via diethyleneglycol connectors enhanced the extraction efficiency (2-5 orders in magnitude) for actinides(III) and lanthanides(III) from acidic solutions compared to organic TODGA molecules without COSANs or synergetic mixtures of organic TODGA and chloroprotected cobalt bis(dicarbollide) [14]. 
In this work we report an extended series of the new extracting agents along with a deeper discussion of the scope and limitation of the synthetic methods used for their synthesis and we present here also more details on the compounds characterization by ${ }^{11} \mathrm{~B},{ }^{1} \mathrm{H},{ }^{13} \mathrm{C}$ NMR spectroscopy, inclusive complete peak assignments, and mass spectrometry (see the Supporting Information). A detailed study of extraction efficiency of extractants, stability and possibility of back extraction will be given. The derivatives differ in substituents on the amidic nitrogen atom of diglycolamide group attached to the COSAN cages. The influence of the substituents as well as effect of diluents and of the composition of the aqueous phase on the extraction efficiency for $\mathrm{Am}(\mathrm{III})$ and $\mathrm{Eu}(\mathrm{III})$ will be portrayed.

\section{Experimental}

\subsection{General}

All syntheses were carried out with the use of standard vacuum or inert-atmosphere techniques as described by Shriver [15], although some operations, such as column chromatography, were carried out in air atmosphere. The starting zwitterionic ammonium derivatives closo$\left[\left(8-\mathrm{RNH}_{2}-\left(\mathrm{C}_{2} \mathrm{H}_{4} \mathrm{O}\right)_{2}-1,2-\mathrm{C}_{2} \mathrm{~B}_{9} \mathrm{H}_{10}\right)\left(1^{\prime}, 2^{\prime}-\mathrm{C}_{2} \mathrm{~B}_{9} \mathrm{H}_{11}\right)-3,3^{\prime}-\right.$ $\mathrm{Co}(\mathrm{III})]^{0}\left(\mathrm{R}=n-\mathrm{C}_{4} \mathrm{H}_{9}, n-\mathrm{C}_{8} \mathrm{H}_{17}, t-\mathrm{C}_{8} \mathrm{H}_{17}, n-\mathrm{C}_{12} \mathrm{H}_{25},-\mathrm{C}_{6} \mathrm{H}_{4}-\right.$ 4- $\mathrm{CH}_{3},-\mathrm{CH}_{2} \mathrm{C}_{6} \mathrm{H}_{5}$ ) were prepared and characterized according to the published procedures $[10,16]$. The compounds, isolated by chromatography, in amounts of $2 \mathrm{~g}$, were dissolved in an $\mathrm{Et}_{2} \mathrm{O}$ - ethylacetate mixture $(30 \mathrm{~mL}$ per $1 \mathrm{~g})$ and washed first with $\mathrm{HCl}(3 \mathrm{M}, 4 \times 20 \mathrm{~mL})$, then with water $(4 \times 20 \mathrm{~mL})$ to remove residual sodium ions. The organic phase was separated and after addition of water $(5 \mathrm{~mL})$ evaporated to dryness in vacuum. The ammonium derivatives were dried at $80^{\circ} \mathrm{C}$ for $8 \mathrm{~h}$ before use. THF was dried over $\mathrm{Na}$ metal and sodium diphenyl ketyl; $\mathrm{CH}_{2} \mathrm{Cl}_{2}$ was dried over $\mathrm{P}_{2} \mathrm{O}_{5}$, and the solvents were freshly distilled before use. High surface sodium hydride $(96 \%)$ with a BET surface area of about $1.5 \mathrm{~m}^{2}$ per gram was used (research product of the Institute of Inorganic Chemistry AS CR, Řež, Czech Republic). The diglycolyl acid dichloride (95\%) was purchased from Aldrich and distilled in vacuum before use. Other chemicals were reagent or analytical grade and were used as purchased. Preparative column chromatography was carried out on silica gel (Aldrich 200-400 mesh). The purity of the individual chromatographic fractions was monitored by analytical TLC on Silufol ${ }^{\circledR}$ (Lachema, Votice, Czech Republic, silica gel on an aluminium foil, starch as the binder; yellow-orange spots) and was simultaneously controlled by Ion Pair Reverse Phase HPLC (IP-RP-HPLC) method [17] (see also the Supporting Information).

\subsection{General synthetic procedure for $\mathrm{Na}_{2}(1-9)$}

The zwitterionic ammonium derivatives prepared using a known procedure $[10,16,18](3.6 \mathrm{mmol})$ were dried in vacuum at $60^{\circ} \mathrm{C}$ for $12 \mathrm{~h}$, dissolved in THF $(100 \mathrm{~mL})$ and then solid $\mathrm{NaH}(95 \%, 360 \mathrm{mg}, 14.4 \mathrm{mmol})$ was added. The resulting slurry was stirred at room temperature for $2 \mathrm{~h}$. Then diglycolyl acid dichloride (95\%, Aldrich $210 \mu \mathrm{L}$, $1.8 \mathrm{mmol})$ in THF $(10 \mathrm{~mL})$ was dropwise added during
120 min using a syringe. The content of the reaction flask was heated at $60^{\circ} \mathrm{C}$ (bath temperature) until the spot of starting species almost disappeared on the TLC (16-48 h). After cooling, ethanol $(3 \mathrm{~mL})$ was carefully added to the reaction mixture followed by acetic acid $(0.2 \mathrm{~mL})$, the volatiles were removed in vacuum. The crude products were dissolved in $\mathrm{CH}_{2} \mathrm{Cl}_{2}$ (eventually with addition of several drops of $\left.\mathrm{CH}_{3} \mathrm{CN}\right)$, chromatographed on silica gel column $(25 \times$ $2.5 \mathrm{~cm}$ I.D., high purity silica gel Aldrich) and eluted with $\mathrm{CH}_{2} \mathrm{Cl}_{2}$ to remove small amounts of the unreacted ammonium derivative and then with a $\mathrm{CH}_{2} \mathrm{Cl}_{2}-\mathrm{CH}_{3} \mathrm{CN}$ mixture $(3: 1$ b.v.). The main orange band eluting after that of the ammonium derivative was collected and the solvents were removed under vacuum. The solids were dissolved in $\mathrm{CH}_{2} \mathrm{Cl}_{2}$ (addition of a few drops of $\mathrm{MeOH}$ ), carefully layered with hexane and left to crystallize for three days, then the solids were either collected by filtration or decanted and dried in vacuum for $5 \mathrm{~h}$. The compounds 1 and $\mathbf{6}$ were isolated as side products from the reaction with the $t$-octylammonium derivative, the details are given in experimental part for each of these two compounds.

$\mathrm{Na}_{2} \mathrm{I}\left({ }^{1} \mathrm{R}={ }^{2} \mathrm{R}=\mathrm{H}\right)$ : was isolated by chromatography as the main product from the reaction with the $\left[\left(8-t-\mathrm{C}_{8} \mathrm{H}_{17}-\right.\right.$ $\left.\left.\mathrm{RNH}_{2}-\left(\mathrm{C}_{2} \mathrm{H}_{4} \mathrm{O}\right)_{2}-1,2-\mathrm{C}_{2} \mathrm{~B}_{9} \mathrm{H}_{10}\right)\left(1^{\prime}, 2^{\prime}-\mathrm{C}_{2} \mathrm{~B}_{9} \mathrm{H}_{11}\right)-3,3^{\prime}-\mathrm{Co}(\mathrm{III})\right]^{0}$ derivative. Whereas elution with $\mathrm{CH}_{2} \mathrm{Cl}_{2}-\mathrm{CH}_{3} \mathrm{CN}(3: 1)$ solvent mixture provided the expected product $\mathrm{Na}_{2} \mathbf{6}$ as the faster moving band, continued elution with eluents containing increased content of acetonitrile $(3: 2)$ and then $(1: 1)$ led to successive collecting of the main orange band containing the completely dealkylated product $\mathrm{Na}_{2} \mathbf{1}$ and compound $\mathrm{Na}_{2} 7$ with one $t$-octyl group in the structure. The mobile phase was evaporated and the crude products were purified by crystallization using the procedure described above yielding $0.51 \mathrm{~g}(23 \%) ; \mathrm{Na}_{2} 2\left({ }^{1} \mathrm{R}={ }^{2} \mathrm{R}=n-\mathrm{C}_{4} \mathrm{H}_{9}\right)$ : yield $1.14 \mathrm{~g}$ (57\%); $\mathrm{Na}_{2} 3\left({ }^{1} \mathrm{R}={ }^{2} \mathrm{R}=n-\mathrm{C}_{6} \mathrm{H}_{13}\right)$ : yield $1.1 \mathrm{~g}(53 \%) ; \mathrm{Na}_{2} 4$ $\left({ }^{1} \mathrm{R}={ }^{2} \mathrm{R}=n-\mathrm{C}_{8} \mathrm{H}_{17}\right)$ : yield $1.97 \mathrm{~g}(88 \%) ; \mathrm{Na}_{2} \mathbf{5}\left({ }^{1} \mathrm{R}={ }^{2} \mathrm{R}=n\right.$ $\left.\mathrm{C}_{12} \mathrm{H}_{25}\right)$ : yield $1.72 \mathrm{~g}(70 \%) ; \mathrm{Na}_{2} \mathbf{6}\left({ }^{1} \mathrm{R}={ }^{2} \mathrm{R}=t-\mathrm{C}_{8} \mathrm{H}_{17}\right)$ : yield $0.12 \mathrm{~g}(5 \%) ; \mathrm{Na}_{2} 7\left({ }^{1} \mathrm{R}=t-\mathrm{C}_{8} \mathrm{H}_{17},{ }^{2} \mathrm{R}=\mathrm{H}\right)$ : This compound was isolated by chromatography along with the derivative $\mathrm{Na}_{2} \mathrm{l}$ as the side product from $t$-octyl cleave during reaction of the $t$-octyl ammonium derivative with diglycolic acid dichloride (see the procedure for $\mathrm{Na}_{2} \mathbf{1}$ above), eluting between the bands of $\mathrm{Na}_{2} 6$ and $\mathrm{Na}_{2} \mathbf{1}$, yield $0.15 \mathrm{~g}$ (6\%); $\mathrm{Na}_{2} 8 \quad\left({ }^{1} \mathrm{R}={ }^{2} \mathrm{R}=\mathrm{C}_{6} \mathrm{H}_{4}-4-\mathrm{CH}_{3}\right)$ : yield $1.05 \mathrm{~g}$ (48\%); $\mathrm{Na}_{2} 9\left({ }^{1} \mathrm{R}={ }^{2} \mathrm{R}=\mathrm{CH}_{2} \mathrm{C}_{6} \mathrm{H}_{5}\right)$ : yield $1.29 \mathrm{~g}(62 \%)$.

All compounds were characterized by TLC $\mathrm{R}_{\mathrm{F}},{ }^{11} \mathrm{~B},{ }^{1} \mathrm{H}$, ${ }^{1} \mathrm{H}\left\{{ }^{11} \mathrm{~B}\right\}$ selective ${ }^{13} \mathrm{C}$, NMR spectrometry and Mass spectrometry with electrospay ionization (ESI-MS). For the detailed data sets, the instrumet setup, and experimental conditions see the Supporting Information.

\subsection{Extraction tests}

The extraction experiments were performed in closed testtubes using $1 \mathrm{~mL}$ of each phase and shaking for $1 \mathrm{~h}$ on a horizontal shaker in a thermostated box at $25 \pm 0.1^{\circ} \mathrm{C}$. After shaking, the test-tubes were centrifuged $(6000 \mathrm{rpm})$ and aliquots of each phase $(0.5 \mathrm{~mL})$ were taken for radioactivity measurement using a single-channel $\gamma$ analyzer with a $\mathrm{NaI}(\mathrm{Tl})$ well detector. The distribution of $\mathrm{Eu}(\mathrm{III})$ and Am(III) was studied using ${ }^{152,154} \mathrm{Eu}$ and ${ }^{241} \mathrm{Am}$ in trace 
amounts (radiochemical purity). The distribution ratio of the metal ions was determined as a ratio of the measured radioactivities in the organic and in the aqueous phases.

For tests of the hydrolytic stability, the organic solutions $\left(1 \times 10^{-3} \mathrm{M}\right.$ extractant in hexyl methyl ketone and $n$ dodecane, $1: 1$ ) were left in continuous contact with $1 \mathrm{M}$ or $3 \mathrm{M} \mathrm{HNO}_{3}$ (one hour of shaking each day, otherwise in static contact). The extractant stability was evaluated through the $\mathrm{Eu}(\mathrm{III})$ extraction coefficient.

\section{Results and discussion}

\subsection{Synthesis}

A series of new anionic ligands 1-9 was prepared with the aim to understand how the modifications of the amidic groups in the anionic TODGA-like molecules can influence the extraction efficiency. Another goal was to enable selection of optimal substitution allowing to work in less polar solvents. The synthesis of compounds 1-9 consisted of a one step reaction between two equivalents of ammonium derivatives of COSAN and one equivalent of diethyleneglycol acid dichloride (see Fig. 1), similarly as described in our precedent short paper [14]. The particular starting ammonium derivatives were already described and were prepared by known $N$-alkylation of the particular amine $(\mathrm{R}=n$ $\mathrm{C}_{4} \mathrm{H}_{9}, n-\mathrm{C}_{6} \mathrm{H}_{17}, n-\mathrm{C}_{8} \mathrm{H}_{17}, t-\mathrm{C}_{8} \mathrm{H}_{17}, n-\mathrm{C}_{12} \mathrm{H}_{25},-\mathrm{C}_{6} \mathrm{H}_{4}-4-\mathrm{CH}_{3}$, $-\mathrm{CH}_{2} \mathrm{C}_{6} \mathrm{H}_{5}$ ) by ring cleavage of the COSAN-dioxane zwitterion $\left[8-\mathrm{O}\left(\mathrm{CH}_{2} \mathrm{CH}_{2}\right)_{2} \mathrm{O}-\left(1,2-\mathrm{C}_{2} \mathrm{~B}_{11} \mathrm{H}_{10}\right)\left(1^{\prime}, 2^{\prime}-\mathrm{C}_{2} \mathrm{~B}_{11} \mathrm{H}_{11}\right)-3,3^{\prime}-\right.$ $\mathrm{Co}]^{0}[10,16,18]$. All the reactions provided the assumed divalent anionic ligands in good yields (see Experimental) with exception of the $t$-octyl substituted compound $\mathrm{Na}_{2} \mathbf{6}$. This molecule could be isolated only at a low yield (5\%), apparently due to steric shielding effects of the rigid $t$ octyl substituent and possibly also due to the presence of COSAN as the second sterically demanding group, sitting in the vicinity of the reaction centre. Another effect, which undoubtedly contributed to the low yield of this compound, is an easy splitting of one or both $t$-octyl groups from nitro- gen atoms of the amidic functions, proceeding even under reaction conditions successfully employed for other species. Thus, the careful product isolation resulted in isolation of only moderate or low yield (23\% and 6\%) of completely or partly dealkylated products, compounds $\mathrm{Na}_{2} \mathbf{1}$ and $\mathrm{Na}_{2} 7$ resp., from this reaction mixture.

\subsection{Characterization of compounds}

All compounds were characterized by NMR spectroscopy, mass spectrometry, and TLC $\mathrm{R}_{\mathrm{F}}$. The purity of all species has been determined by HPLC methods [17] to be better than $98 \%$. The ${ }^{11} \mathrm{~B},{ }^{1} \mathrm{H}$ and ${ }^{13} \mathrm{C}$ NMR spectra (see the Supporting Information) of 1-9 are completely in agreement with the expected structures and product composition. Only a small difference from expected pattern can be seen in ${ }^{1} \mathrm{H}$ and ${ }^{13} \mathrm{C}$ NMR spectra of the $t$-octyl substituted derivative, which shows a symmetry splitting of the $\{\mathrm{C}=\mathrm{O}\}$ and one of the carborane $\mathrm{CH}$ and $t-\mathrm{C}_{8} \mathrm{H}_{17}$ terminal methyl signals into two resonances of equal intensity. This observation probably suggests a different orientation (trans) of these groups in a sodium complex, and may also explain the comparatively low extraction efficiency of this species (see below). Almost all the compounds exhibit in the $\mathrm{ESI}^{-}$mass spectra less intensive molecular peaks corresponding to $\mathrm{m} / \mathrm{z}$ for divalent anions $[\mathrm{M}]^{2-}$ and the most abundant molecular $\mathrm{m} / \mathrm{z}$ base peaks for $[\mathrm{M}+\mathrm{Na}-2 \mathrm{H}]^{2-}$ ion, suggesting a dimerization (or even more complex behavior) of the sodium salts in solution via hydrogen bridge formation or sodium complexation (for details see the Supporting Information). The monovalent ion $[\mathrm{M}+\mathrm{Na}]^{-}$sodium complex was found only for the compound where $\mathrm{R}=t-\mathrm{C}_{8} \mathrm{H}_{17}$ and $-\mathrm{CH}_{2}-\mathrm{C}_{6} \mathrm{H}_{5}$. For each particular observed ion, the experimental and calculated (using Mass Spectrometric software the EXcalibur) isotopic patterns were in agreement.

\subsection{Extraction results}

Extractions of $\mathrm{Eu}(\mathrm{III})$ and $\mathrm{Am}(\mathrm{III})$ in a solvent mixture of hexyl methyl ketone and $n$-dodecane (HMK/D, $1: 1)$ with

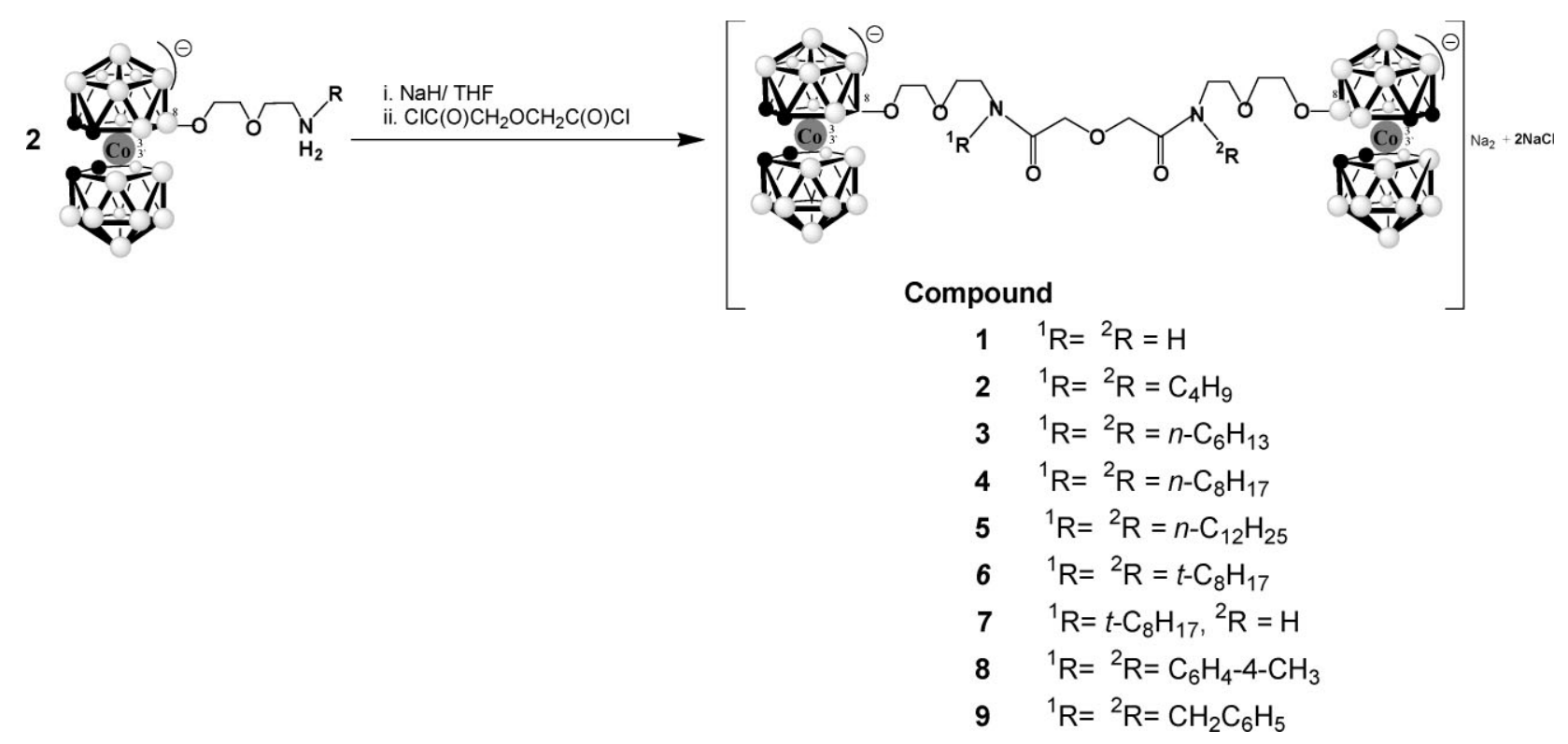

Fig. 1. Reaction pathway used to prepare compounds 1-9. 
Table 1. Eu(III) and Am(III) extraction at variable $\mathrm{HNO}_{3}$ concentration by extractants 1-9.

\begin{tabular}{|c|c|c|c|c|c|c|c|}
\hline \multirow{2}{*}{$\begin{array}{l}\text { Compound } \\
\text { (substituent) }\end{array}$} & \multirow{2}{*}{$\begin{array}{l}\text { Efficiency } \\
\text { selectivity }\end{array}$} & \multicolumn{6}{|c|}{$c\left(\mathrm{HNO}_{3}\right)[\mathrm{M}]$} \\
\hline & & 0.01 & 0.1 & 1 & 2 & 3 & 4 \\
\hline $\mathbf{1}\left(N, N^{\prime}\right.$-di- $n$-hydrogen $)$ & $\begin{array}{l}D_{\mathrm{Eu}} \\
D_{\mathrm{Am}} \\
S F_{\mathrm{Eu} / \mathrm{Am}}\end{array}$ & $\begin{array}{l}>1000 \\
>1000\end{array}$ & $\begin{array}{l}110 \\
88.2 \\
1.25\end{array}$ & $\begin{array}{l}0.111 \\
0.054 \\
2.06\end{array}$ & $\begin{array}{l}0.013 \\
0.005 \\
2.60\end{array}$ & $\begin{array}{l}0.005 \\
0.002 \\
2.50\end{array}$ & $\begin{array}{l}0.003 \\
0.001 \\
3.00\end{array}$ \\
\hline 2 & $\begin{array}{l}D_{\mathrm{Eu}} \\
D_{\mathrm{Am}} \\
S F_{\mathrm{Eu} / \mathrm{Am}}\end{array}$ & $\begin{array}{c}887 \\
>1000\end{array}$ & $\begin{array}{c}732 \\
> \\
1000\end{array}$ & $\begin{array}{l}40.6 \\
8.83 \\
4.60\end{array}$ & $\begin{array}{l}3.16 \\
0.618 \\
5.11\end{array}$ & $\begin{array}{l}1.11 \\
0.189 \\
5.87\end{array}$ & $\begin{array}{l}0.478 \\
0.070 \\
6.83\end{array}$ \\
\hline $\begin{array}{l}3 \\
\left(N, N^{\prime} \text {-di- } n \text {-hexyl }\right)\end{array}$ & $\begin{array}{l}D_{\mathrm{Eu}} \\
D_{\mathrm{Am}} \\
S F_{\mathrm{Eu} / \mathrm{Am}}\end{array}$ & 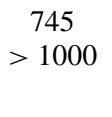 & $\begin{array}{c}626 \\
> \\
1000\end{array}$ & $\begin{array}{l}11.6 \\
3.47 \\
3.34\end{array}$ & $\begin{array}{l}0.922 \\
0.220 \\
4.19\end{array}$ & $\begin{array}{l}0.312 \\
0.065 \\
4.80\end{array}$ & $\begin{array}{l}0.123 \\
0.024 \\
5.13\end{array}$ \\
\hline$\underset{\left(N, N^{\prime} \text {-di- } n \text {-octyl }\right)}{ }$ & $\begin{array}{l}D_{\mathrm{Eu}} \\
D_{\mathrm{Am}} \\
S F_{\mathrm{Eu} / \mathrm{Am}}\end{array}$ & $\begin{array}{c}710 \\
> \\
1000\end{array}$ & $\begin{array}{c}606 \\
>1000\end{array}$ & $\begin{array}{l}19.5 \\
5.91 \\
3.30\end{array}$ & $\begin{array}{l}1.71 \\
0.364 \\
4.70\end{array}$ & $\begin{array}{l}0.607 \\
0.108 \\
5.62\end{array}$ & $\begin{array}{l}0.268 \\
0.041 \\
6.54\end{array}$ \\
\hline $\begin{array}{l}5 \\
\left(N, N^{\prime} \text {-di- } n \text {-dodecyl }\right)\end{array}$ & $\begin{array}{l}D_{\mathrm{Eu}} \\
D_{\mathrm{Am}} \\
S F_{\mathrm{Eu} / \mathrm{Am}}\end{array}$ & $\begin{array}{c}528 \\
>1000\end{array}$ & $\begin{array}{l}>1000 \\
>1000\end{array}$ & $\begin{array}{l}10.5 \\
3.16 \\
3.32\end{array}$ & $\begin{array}{l}0.843 \\
0.198 \\
4.26\end{array}$ & $\begin{array}{l}0.285 \\
0.057 \\
5.00\end{array}$ & $\begin{array}{l}0.117 \\
0.020 \\
5.85\end{array}$ \\
\hline $\begin{array}{l}\mathbf{6} \\
\left(N, N^{\prime} \text {-di-t-octyl }\right)\end{array}$ & $\begin{array}{l}D_{\mathrm{Eu}} \\
D_{\mathrm{Am}} \\
S F_{\mathrm{Eu} / \mathrm{Am}}\end{array}$ & $\begin{array}{c}340 \\
>1000\end{array}$ & $\begin{array}{l}198 \\
177 \\
1.12\end{array}$ & $\begin{array}{l}0.755 \\
0.276 \\
2.74\end{array}$ & $\begin{array}{l}0.102 \\
0.028 \\
3.64\end{array}$ & $\begin{array}{l}0.050 \\
0.012 \\
4.17\end{array}$ & $\begin{array}{l}0.029 \\
0.005 \\
5.80\end{array}$ \\
\hline $\begin{array}{l}7 \\
(N-t \text {-octyl })\end{array}$ & $\begin{array}{l}D_{\mathrm{Eu}} \\
D_{\mathrm{Am}} \\
S F_{\mathrm{Eu} / \mathrm{Am}}\end{array}$ & $\begin{array}{c}372 \\
>1000\end{array}$ & $\begin{array}{l}349 \\
533\end{array}$ & $\begin{array}{l}1.29 \\
0.361 \\
3.57\end{array}$ & $\begin{array}{l}0.096 \\
0.022 \\
4.36\end{array}$ & $\begin{array}{l}0.026 \\
0.005 \\
5.20\end{array}$ & $\begin{array}{l}0.007 \\
0.001 \\
7.00\end{array}$ \\
\hline $\begin{array}{l}8 \\
\left(N, N^{\prime} \text {-ditolyl }\right)\end{array}$ & $\begin{array}{l}D_{\mathrm{Eu}} \\
D_{\mathrm{Am}} \\
S F_{\mathrm{Eu} / \mathrm{Am}}\end{array}$ & $\begin{aligned} & 445 \\
> & 1000\end{aligned}$ & $\begin{array}{l}>1000 \\
>1000\end{array}$ & $\begin{array}{l}25.6 \\
28.1 \\
0.91\end{array}$ & $\begin{array}{l}1.83 \\
1.82 \\
1.01\end{array}$ & $\begin{array}{l}0.573 \\
0.513 \\
1.12\end{array}$ & $\begin{array}{l}0.165 \\
0.132 \\
1.25\end{array}$ \\
\hline 9 & $\begin{array}{l}D_{\mathrm{Eu}} \\
D_{\mathrm{Am}} \\
S F_{\mathrm{Eu} / \mathrm{Am}}\end{array}$ & $\begin{array}{c}473 \\
>1000\end{array}$ & $\begin{array}{l}342 \\
772\end{array}$ & $\begin{array}{l}45.2 \\
11.5 \\
3.93\end{array}$ & $\begin{array}{l}4.09 \\
0.832 \\
4.92\end{array}$ & $\begin{array}{l}1.50 \\
0.267 \\
5.62\end{array}$ & $\begin{array}{l}0.728 \\
0.108 \\
6.74\end{array}$ \\
\hline
\end{tabular}

$1 \times 10^{-3} \mathrm{M}$ extractant in HMK/D $(1: 1) ;{ }^{152,154} \mathrm{Eu}$ and ${ }^{241} \mathrm{Am}$ tracers, variable nitric acid concentration.

compounds 1-9 are summarized in Table 1. All compounds are efficient extraction agents at low extractant concentration and down to $\mathrm{pH} 1$ ( $D_{\mathrm{M}}$ close or higher than 100). In most cases, the dependencies of $D_{\mathrm{M}}$ on the acidity show a rapid decrease. Exceptions are those with a maximum occurring close to $0.1 \mathrm{M} \mathrm{HNO}_{3}$. The existence of these maxima can probably be explained by competition of protonized species of the extractant molecule. From these dependencies, it is evident that the extraction behaviours of trivalent lanthanides/actinides using compounds 1-9 based on cobalt bis(dicarbollide) differ markedly from that using TODGA as an extractant. In the case of TODGA, the extractability enhances with increasing $\mathrm{HNO}_{3}$ concentrations. This can be attributed to the fact that TODGA extracts trivalent cations as ion pair accompanied by anion $\mathrm{NO}_{3}{ }^{-}$, and thus the effective extraction is achieved under highly acidic conditions [19]. In contrast, the efficiency of extractants 1-9 with cobalt bis(dicarbollide) ions decreases with increased acidity. These compounds behave as ion exchangers. As an example of this fact is the plot of the distribution ratios of $\mathrm{Eu}(\mathrm{III})$ and $\mathrm{Am}(\mathrm{III})$ vs. higher nitric acid concentration by ligand 4 with the log-log slopes close to -3 (see Fig. 2), which indicate an exchange of one Eu(III)

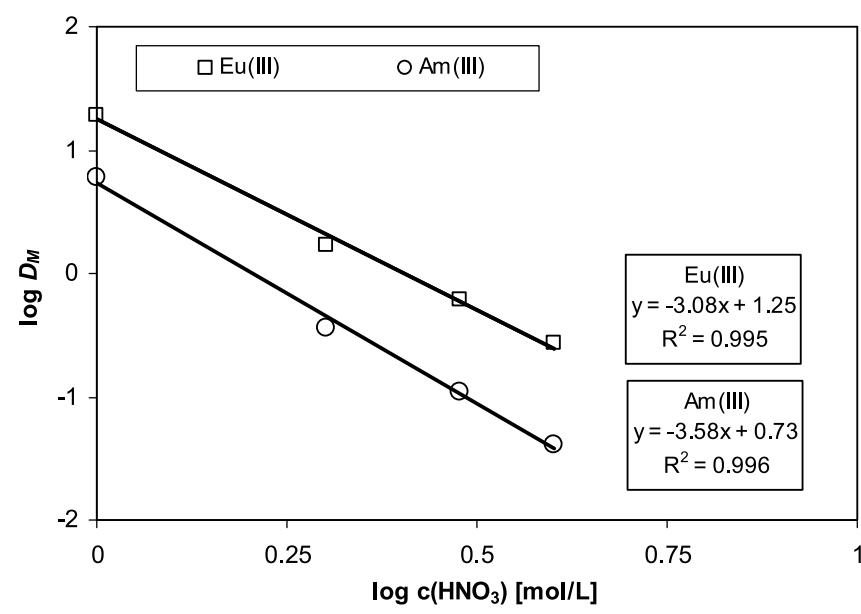

Fig. 2. Plot of distribution ratios vs. $\mathrm{HNO}_{3}$ concentration by extractant $4\left(1 \times 10^{-3} \mathrm{M}\right.$ extractant 4 in HMK/D $(1: 1) ;{ }^{152,154} \mathrm{Eu}$ and ${ }^{241} \mathrm{Am}$ tracers, variable nitric acid concentration).

or Am(III) ions for three protons if activity coefficient are neglected.

It is obvious that from all compounds with an $n$-alkyl chain on the amidic nitrogen atom of the diglycolamide 
Table 2. Eu(III) and Am(III) extraction in different solvents by extractant 4

\begin{tabular}{|c|c|c|c|c|c|c|c|}
\hline \multirow[t]{2}{*}{ Solvent } & \multirow{2}{*}{$\begin{array}{l}\text { Efficiency } \\
\text { selectivity }\end{array}$} & \multicolumn{6}{|c|}{$c\left(\mathrm{HNO}_{3}\right)[\mathrm{M}]$} \\
\hline & & 0.01 & 0.1 & 1 & 2 & 3 & 4 \\
\hline \multirow[t]{3}{*}{$\mathrm{NB}^{a}$} & & $>1000$ & $>1000$ & 3.27 & 0.248 & 0.062 & 0.033 \\
\hline & $D_{\mathrm{Am}}$ & $>1000$ & $>1000$ & 0.983 & 0.073 & 0.018 & 0.008 \\
\hline & $S F_{\mathrm{Eu} / \mathrm{Am}}$ & & & 3.33 & 3.40 & 3.44 & 4.13 \\
\hline \multirow[t]{3}{*}{ DClE } & $D_{\mathrm{Eu}}$ & 379 & $>1000$ & 248 & 14.1 & 3.36 & 0.934 \\
\hline & $D_{\text {Am }}$ & 307 & $>1000$ & 38.6 & 2.80 & 0.636 & 0.218 \\
\hline & $S F_{\mathrm{Eu} / \mathrm{Am}}$ & 1.23 & & 6.42 & 5.04 & 5.28 & 4.28 \\
\hline \multirow[t]{3}{*}{ HMK } & $D_{\mathrm{Eu}}$ & $>1000$ & 47.0 & 0.046 & 0.010 & 0.008 & 0.006 \\
\hline & $D_{\mathrm{Am}}$ & $>1000$ & 16.8 & 0.023 & 0.004 & 0.002 & 0.002 \\
\hline & $S F_{\mathrm{Eu} / \mathrm{Am}}$ & & 2.80 & 2.00 & 2.50 & 4.00 & 3.00 \\
\hline \multirow{3}{*}{$\begin{array}{l}\text { HMK/D } \\
(1: 1)\end{array}$} & $D_{\mathrm{Eu}}$ & 710 & 606 & 19.5 & 1.71 & 0.607 & 0.268 \\
\hline & $D_{\mathrm{Am}}$ & $>1000$ & $>1000$ & 5.91 & 0.364 & 0.108 & 0.041 \\
\hline & $S F_{\mathrm{Eu} / \mathrm{Am}}$ & & & 3.30 & 4.70 & 5.62 & 6.54 \\
\hline \multirow[t]{3}{*}{ Cumene } & & $>1000$ & $>1000$ & 720 & 224 & 67.0 & 24.0 \\
\hline & $D_{\text {Am }}$ & 792 & $>1000$ & 439 & 53.9 & 12.8 & 3.87 \\
\hline & $S F_{\mathrm{Eu} / \mathrm{Am}}$ & & & 1.64 & 4.16 & 5.23 & 6.20 \\
\hline \multirow[t]{3}{*}{ DOS } & $D_{\text {Еu }}$ & 232 & 950 & 170 & 22.4 & 3.18 & 1.80 \\
\hline & $D_{\text {Am }}$ & 123 & $>1000$ & 44.8 & 3.23 & 0.775 & 0.352 \\
\hline & $S F_{\mathrm{Eu} / \mathrm{Am}}$ & 1.89 & & 3.79 & 6.93 & 4.10 & 5.11 \\
\hline \multirow[t]{3}{*}{ Toluene } & $D_{\text {Еu }}$ & 220 & 371 & 465 & 116 & 31.5 & 11.7 \\
\hline & $D_{\mathrm{Am}}$ & 787 & 606 & 164 & 24.6 & 5.74 & 1.95 \\
\hline & $S F_{\mathrm{Eu} / \mathrm{Am}}$ & & & 2.83 & 4.72 & 5.49 & 6.00 \\
\hline
\end{tabular}

$1 \times 10^{-3} \mathrm{M}$ extractant 4 in respective solvent; ${ }^{152,154} \mathrm{Eu}$ and ${ }^{241} \mathrm{Am}$ tracers, variable nitric acid concentration; a: slight turbidity of the aqueous phase was observed.

group, the compound $\mathbf{2}$ with dibutyl substituents provides the highest distribution ratios. Other compounds with longer $n$-alkyl chains display lower extraction efficiencies. It is also evident that the compounds with $n$-octyl substituents extract trivalent radionuclides significantly better compared to compounds with one or two $t$-octyl substituents. Reduced extraction efficiencies of compounds with one or two $t$ octyl substituents can be ascribed to steric hindrances. Compounds 8 and $\mathbf{9}$ with aryl substituents exhibit good extraction efficiencies, similar to those of compounds with $n$-alkyl chains.

All tested derivatives (except compound 8) had at higher nitric acid concentrations $(>1 \mathrm{M})$ a greater affinity for lanthanides(III) than for actinides(III) (with $S F_{\mathrm{Eu} / \mathrm{Am}}$ ranging for most compounds from 3 to 7). The higher selectivity for europium(III) over americium(III) corresponds to that observed for organic diglycolamide compounds [20]. For compound $\mathbf{8}$ with tolyl substituents no selectivity for the actinide(III)/lanthanide(III) separation was observed probably due to the presence of two weakly basic nitrogen centers in its structure.

For further systematic extraction studies the effective extractant $\mathbf{4}$ was selected. The extractant $\mathbf{4}$ had good solubility in solvents like nitrobenzene (NB), 1,2-dichlorethane (DClE), toluene, hexyl methyl ketone (HMK), mixture of hexyl methyl ketone and $n$-dodecane (HMK/D), but was less soluble in cumene and di-n-octyl sebacate (DOS), and not soluble in non-polar solvent $n$-dodecane (D). The influence of the acidity on the europium(III) and americium(III) extractions using extractant $\mathbf{4}$ in different solvents is summarized in Table 2.

In most cases, a decrease of distribution ratios with increase of acidity was observed. Exceptions are again cases with maxima occurring close to $0.1 \mathrm{M} \mathrm{HNO}_{3}$, which are difficult to explain. In the case of usage of nitrobenzene as diluent, the unexplained slight turbidity in the aqueous phase was observed. The highest extraction efficiency was observed in cumene, di- $n$-octyl sebacate (DOS), and toluene $\left(D_{\text {Eu }}\right.$ higher than 1 even at $\left.4 \mathrm{M} \mathrm{HNO}_{3}\right)$. However, the very high distribution ratios are detrimental for back-extraction. In view of a solvent technological acceptability, aromatic solvents (due to their possible nitration) and halogenated alkanes (considering ecological viewpoint) were excluded. Therefore, a solvent mixture of hexyl methyl ketone and $n$-dodecane (HMK/D) fulfilling technological and also ecological criteria, but having lower $D$ values without loosing $\mathrm{Eu}(\mathrm{III}) / \mathrm{Am}$ (III) separation efficiency, was selected for the following experiments. As can be seen, the extraction efficiency of $\mathrm{Eu}(\mathrm{III})$ and $\mathrm{Am}$ (III) from acidic solutions by 4 into pure HMK is the lowest from all tested solvents, probably due to the competition with the protonized solvent. The aliphatic ketones can be used as extracting agents themselves, methyl-isobutyl ketone (MIBK) has been used extensively to extract different metal ions in the past, including uranium. However, HMK seems to be inert solvent to $f$-elements. Additionally, the extraction properties of extractant may be easily modified by changing the volume ratio of hexyl methyl ketone and $n$-dodecane. 


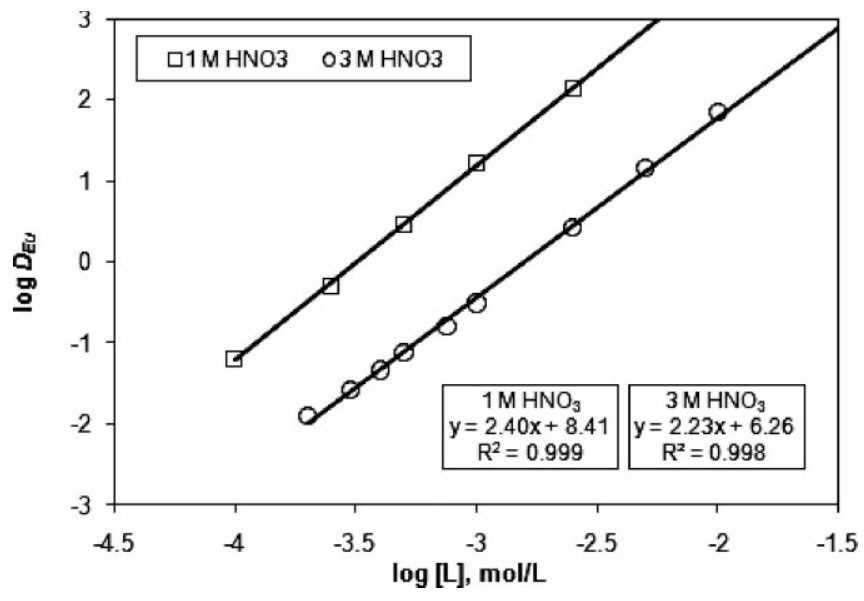

Fig. 3. Complex stoichiometry determination by slope analysis (variable extractant 4 concentrations in HMK/D $(1: 1) ;{ }^{152,154} \mathrm{Eu}$ tracer in $1 \mathrm{M}$ or $3 \mathrm{M} \mathrm{HNO}_{3}$ ).

The influence of the ligand concentration on $\mathrm{Eu}(\mathrm{III})$ extraction was studied at two acidities $\left(1 \mathrm{M}\right.$ and $\left.3 \mathrm{M} \mathrm{HNO}_{3}\right)$. The results presented in Fig. 3 demonstrate that $\log D_{\mathrm{Eu}}$ is proportional to the concentration of extractant 4 , the loglog slopes for both acid concentrations vary in the interval $\alpha=2.2-2.4$. From the slope analysis it follows that $\left[\mathrm{Eu}(\mathrm{L})_{2}\right]^{-}$is probably a dominant complex extracted in the particular organic phase. Thus, the Eu(III) cation is deemed to be trapped between two ligand molecules, the negative charge of this species being probably compensated by hydrogen ions. The occurrence of some higher aggregates is also possible.

For a technological extraction process development, the recovery of actinides(III) and lanthanides(III) from the loaded organic phase is necessary. For this purpose, several complexing agents were tested (e.g. citric acid and their salts, oxalic acid and their salts, EDTA, diethylenetriamine pentaacetic acid - DTPA). In all experiments Eu(III) was used as the surrogate for Am(III). Table 3 shows the results for the europium(III) stripping with the most effective strip solutions. From the point of view of the consecutive treatment of $\mathrm{Am}(\mathrm{III}) / \mathrm{Eu}(\mathrm{III})$ product, the ammonium salts are preferable. Therefore, the effective stripping agents are ammonium citrate or the combination of ammonium salts of DTPA and citric acid. The choice of a suitable back-extraction solution will depend on the efficacy of extraction/stripping of the Ln(III)/An(III) group from other

Table 3. Eu(III) back-extraction from loaded organic phase by 4 .

\begin{tabular}{lcc}
\hline Back-extraction solution & $\mathrm{pH}$ & $D_{\mathrm{Eu}}$ \\
& & \\
\hline $1 \mathrm{M}$ sodium citrate & 8.1 & $<0.001$ \\
$1 \mathrm{M} \mathrm{ammonium}$ citrate & 4.9 & 0.012 \\
$1 \mathrm{M} \mathrm{ammonium}$ citrate & $7.9^{a}$ & 0.005 \\
$0.25 \mathrm{M}\left(\mathrm{NH}_{4}\right)_{2} \mathrm{H}_{3} \mathrm{DTPA}$ & $7.6^{a}$ & 0.559 \\
$0.25 \mathrm{M} \mathrm{Na} \mathrm{DTPA}_{5}+1 \mathrm{M} \mathrm{Na}$ citrate & $7.5^{b}$ & 0.001 \\
$0.25 \mathrm{M}\left(\mathrm{NH}_{4}\right)_{2} \mathrm{H}_{3} \mathrm{DTPA}+1 \mathrm{M} \mathrm{Na}$ citrate & $7.5^{a}$ & 0.002 \\
$0.25 \mathrm{M}\left(\mathrm{NH}_{4}\right)_{2} \mathrm{H}_{3} \mathrm{DTPA}+1 \mathrm{M} \mathrm{NH}_{4}$ citrate & $7.5^{a}$ & 0.001 \\
\hline
\end{tabular}

a: $\mathrm{pH}$ adjusted by $\mathrm{NH}_{4} \mathrm{OH}$; b: $\mathrm{pH}$ adjusted by $\mathrm{NaOH}$;

Extraction conditions: $1 \times 10^{-2} \mathrm{M}$ extractant 4 in $\mathrm{HMK} / \mathrm{D}(1: 1)$;

$2 \times 10^{-3} \mathrm{M} \mathrm{Eu}\left(\mathrm{NO}_{3}\right)_{3}$ in $3 \mathrm{M} \mathrm{HNO}_{3} . D_{\text {Eu }}=3.86$ in extraction step. fission products present in the PUREX feed. A corresponding study is underway using a simulated PUREX feed.

The hydrolytic stabilities of $\mathbf{4}$ in a HMK/D solvent mixture $(1: 1)$ in contact with $1 \mathrm{M}$ and $3 \mathrm{M}$ nitric acid, which are relevant for acidic HLW, were studied. The results indicate that the extractant is fairly stable at both nitric acid concentrations where about $90 \%$ of $\mathrm{Eu}(\mathrm{III})$ extraction even after a month of contact was obtained. Additionally, no significant difference of the stability of the extracting phase with 4 in $\mathrm{HMK} / \mathrm{D}(1: 1)$ towards $\mathrm{HNO}_{3}$ with a potential oxidative attack compared to a non oxidative acid such as $\mathrm{HCl}$ was observed.

\section{Conclusions}

The compounds bearing two cobalt bis(dicarbollide) $\left(1^{-}\right)$ anions covalently bound to the diglycolic acid platform by amidic bonds via flexible diethyleneglycol connectors has been successfully prepared and adequately characterized. All tested compounds proved to be efficient extraction agents for $\mathrm{Eu}(\mathrm{III})+\mathrm{Am}(\mathrm{III})$ extraction from acidic nitrate media. A steep decrease of the distribution ratios at higher acidities $(\geq 1 \mathrm{M})$ can be compensated by an increase of extractant concentration. It was found that the extraction ability of extractants depends on the length of the alkyl substituent chain on the amidic nitrogen atom of the diglycolamide group. The most prospective compound is $\mathrm{X}-\left[\left(8-\mathrm{CH}_{2}-\mathrm{CH}_{2} \mathrm{O}\right)_{2}-\left(1,2-\mathrm{C}_{2} \mathrm{~B}_{9} \mathrm{H}_{10}\right)\left(1^{\prime}, 2^{\prime}-\mathrm{C}_{2} \mathrm{~B}_{9} \mathrm{H}_{11}\right)-\right.$ $\left.3,3^{\prime}-\mathrm{Co}\right]_{2}$, where the central amidic unit $\mathrm{X}$ corresponds to $\left[\left(n-\mathrm{C}_{8} \mathrm{H}_{17}-\mathrm{NCOCH}_{2}\right)_{2} \mathrm{O}\right]$. This extractant is soluble in a low polar solvent mixture of hexyl methyl ketone and $n$-dodecane, which is the best diluent to achieve a good compromise between extraction and back-extraction properties. The chemical stability of this compound in $3 \mathrm{M} \mathrm{HNO}_{3}$ is reasonably good. The extractant enables a good extraction of trivalent radionuclides, which can be consecutively effectively stripped by complexants. Further studies using the extractant for its possible technological applications are planned.

Acknowledgment. We thank for partial support from Grant Agency of the Czech Republic (Project No. 104/09/0668), Radioactive Waste Repository Authority (Project 2007/006/Šumb and 2009/002/Šu), Project LC-523 from Ministry of Education, and Research Plan AV0Z40320502 from AS CR.

\section{References}

1. Christiansen, B., Apostolidis, C., Courson, O., Malmbeck, R., Carlos, R., Pagliosa, G., Römer, K., Serrano-Purroy, D., Glatz, J. P.: Advanced aqueous reprocessing in P\&T strategies: process demonstrations on genuine fuels and targets. Radiochim. Acta 92(8), 475 (2004).

2. Mathur, J. N., Murali, M. S., Nash, K. L.: Actinide partitioning a review. Solv. Extr. Ion Exch. 19(3), 357 (2001).

3. Schulz, W. W., Horwitz, E. P.: The TRUEX process and the management of liquid TRU waste. Sep. Sci. Technol. 23, 1191 (1988).

4. Malmbeck, R., Courson, O., Pagliosa, G., Romer, K., Satmark, B., Glatz, J. P., Baron, P.: Partitioning of minor actinides from HLLW using the DIAMEX process. Part 2 - "Hot" continuous countercurrent experiment. Radiochim. Acta 88(12), 865 (2000).

5. Liu, X., Liang, J., Xu, J.: Simplified Chinese TRPO process to extract and recover transuranium elements from high level liquid waste. Solv. Extr. Ion Exch. 22, 163 (2004). 
6. Magnusson, D., Christiansen, B., Glatz, J. P., Malmbeck, R., Modolo, G., Serrano-Purroy, D., Sorel, Ch.: Demonstration of a TODGA based extraction process for the partitioning of minor actinides from a PUREX raffinate. Part II: Centrifugal contactor run using genuine fuel solution. Solv. Extr. Ion Exch. 27(1), 26 (2009).

7. Ansari, S. A., Prabhu, D. R., Gujar, R. B., Kanekar, A. S., Rajeswari, B., Kulkarni, M. J., Murali, M. S., Babu, Y., Natarajan, V., Rajeswari, S., Suresh, A., Manivannan, R., Antony, M. P., Srinivasan, T. G., Manchanda, V. K.: Counter-current extraction of uranium and lanthanides from simulated high-level waste using $N, N, N^{\prime}, N^{\prime}$-tetraoctyl diglycolamide. Sep. Sci. Technol. 66(1), 118 (2009).

8. Herbst, R. S., Law, J. D., Todd, T. A., Romanovskiy, V. N., Smirnov, I. V., Babain, V. A., Esimantovskiy, V. M., Zaitsev, B. N.: Development of the universal extraction (UNEX) process for the simultaneous recovery of $\mathrm{Cs}, \mathrm{Sr}$, and actinides from acidic radioactive wastes. Sep. Sci. Technol. 38, 2685 (2003).

9. Grüner, B., Kvíčalová, M., Plešek, J., Šícha, V., Císařová, I., Lučaníková, M., Selucký, P.: Cobalt bis(dicarbollide) ions functionalized by CMPO-like groups attached to boron by short bonds, efficient extraction agents for separation of trivalent $f$ block elements from highly acidic nuclear waste. J. Organomet. Chem. 694(11), 1678 (2009).

10. Selucký, P., Rais, J., Lučaníková, M., Grüner, B., Kvíčalová, M., Fejfarová, K., Císařová, I.: Lanthanide and actinide extractions with anionic ligands based on cobalt bis(dicarbollide) ions with covalently bonded CMPO functions, Radiochim. Acta 96, 273 (2008) and references therein.

11. Sivaev, I. B., Bregadze, V. I.: Chemistry of cobalt bis(dicarbollides). A review. Collect. Czech. Chem. Commun. 64, 783 (1999).

12. Plešek, J.: Potential applications of the boron cluster compounds. Chem. Rev. 92, 269 (1992).
13. Mikulášek, L., Grüner, B., Dordea, C., Rudzevich, V., Böhmer, V., Haddaoui, J., Hubscher, V., Neu, F. A., Čáslavský, J., Selucký, P.: Tert-butyl-calix[4]arenes substituted at the narrow rim with cobalt bis(dicarbollide) $\left(1^{-}\right)$and CMPO groups - new and efficient extractants for lanthanides and actinides. Eur. J. Org. Chem. 28, 4772 (2007) and the references therein.

14. Grüner, B., Kvíčalová, M., Selucký, P., Lučaníková, M.: Anionic TODGA-like ligands with covalently bound cobalt bis(dicarbollide) ions for lanthanide and actinide extractions. J. Organomet. Chem. 695(9), 1261 (2010).

15. Shriver, D. F., Drezdon, M. A.: Manipulation of Air Sensitive Compounds. $2^{\text {nd }}$ Edn., Wiley, New York (1986).

16. Grüner, B., Plešek, J., Báča, J., Císařová, I., Dozol, J. F., Rouquette, H., Viòas, C., Selucký, P., Rais, J.: Cobalt bis(dicarbollide) ions with covalently bonded CMPO groups as selective extraction agents for lanthanide and actinide cations from highly acidic nuclear waste solutions. New J. Chem. 26, 1519 (2002).

17. Grüner, B., Plzák, Z.: High-performance liquid chromatographic separations of boron-cluster compounds. J. Chromatogr. A $\mathbf{7 8 9}$, 497 (1997).

18. Semioshkin, A. A., Sivaev, I. B., Bregadze, V. I.: Cyclic oxonium derivatives of polyhedral boron hydrides and their synthetic applications. Dalton Trans. 977 (2008) and the references therein.

19. Ansari, S. A., Pathak, P. N., Manchanda, V. K., Husain, M., Prasad, A. K., Parmar, V. S.: $N, N, N^{\prime}, N^{\prime}$-tetraoctyl diglycolamide (TODGA): a promising extractant for actinide-partitioning from high-level waste (HLW). Solv. Extr. Ion Exch. 23(4), 463 (2005).

20. Sasaki, Y., Sugo, Y., Suzuki, S., Tachimori, S.: The novel extractants, diglycolamides, for the extraction of lanthanides and actinides in $\mathrm{HNO}_{3}$-n-dodecane system. Solv. Extr. Ion. Exch. 19(1), 21 (2002). 